\title{
THE EFFECT OF MUSIC THERAPY ON PAIN LEVEL IN INFUSION IN CHILDREN 6-12 YEARS OF AGE AT HARAPAN DAN DOA HOSPITAL
}

\author{
Yenni Fusfitasari ${ }^{1}$, Kurniawan Saprihadi ${ }^{2}$ \\ ${ }^{1}$ STIKes Bhakti Husada Bengkulu, ${ }^{2}$ LPK Kazoku Shourai
}

Email: yen.fus@gmail.com

\begin{abstract}
Infusion is an invasive medical procedure that is often performed and causes acute pain and fear in children. Non-pharmacological pain management can be through distraction, one of which is music therapy. The problem in this study is that there are still many complaints of pain in the infusion procedure at Harapan dan Doa Hospital. The purpose of this study was to determine the effect of music therapy on the pain level of infusion in children aged 6-12 years in the Harapan dan Doa Hospital. This type of research is a type of Quasi-Experimental research with a one group design research design. The population is 1305 people and the research sample is 10 people. The type of data used in this research is primary data. Data analysis in this study used univariate and bivariate data analysis with the statistical method of paried sample $t$ test at the 0.05 significance level. The results of this study were the average pain level of patients before being given music therapy was 7.70 and the average pain level of patients after being given music therapy was 5.80. Bivariate Results There is an effect of the effect of music therapy on the pain level of infusion in children aged 6-12 years at Harapan dan Doa Hospital. For officers, it is necessary to improve overall health services, especially regarding non-pharmacological pain intensity management, namely music therapy.
\end{abstract}

\section{Keywords: Music Therapy, Pain Level}

\section{PENDAHULUAN}

Hospitalisasi sering kali menjadi masalah utama yang harus di hadapi oleh seorang anak. Penyakit yang dialaminya ketika menjalani hospitalisasi dapat menyebabkan anak menjadi trauma akibat adanya perubahan dari kondisi sehat. Perpisahan dengan kelurga, kehilanagn kendali, cidera tubuh dan nyeri merupakan stressor utama hospitalisasi pada ank (Mariyam, 2012). Namun, terdapat perbedaan seperti respons anak usia pra sekolah terhadap intervensi persiapan dalam hal penejelasan prosedur dan teknik distraksi lebih baik bila dibandingkan dengan respons anak usia toddler. Anak usia pra sekolah akan bereaksi terhadap 
tindakan penusukan bahkan mungkin bereaksi untuk menarik diri terhadap jarum karena menimbulkan rasa nyeri yang nyata, yang menyebabkan takut terhadap tindakan penusukan (Hockenberry \& Wilson, 2009).

Wong (2013), anak usia sekolah adalah anak pada usia 6- 12 tahun, yang artinya sekolah menjadi pengalaman inti anak. Periode ketika anak-anak dianggap mulai bertanggung jawab atas perilakunya sendiri dalam hubungan dengan orang tua mereka, teman sebaya, dan orang lainnya. Usia sekolah juga merupakan masa anak memperoleh dasar-dasar pengetahuan untuk keberhasilan penyesuaian diri pada kehidupan dan memperoleh keterampilan tertentu. Pemasangan infus merupakan salah satu prosedur medis invasif yang sering dilakukan dan menyebabkan nyeri akut serta ketakutan pada anak- anak (Sikorova \& Hrazdilova, 2011).

Nyeri yang dirasakan oleh setiap anak-anak akan berbeda-beda karena beberapa alasan. Anak-anak yang usianya lebih muda biasanya akan merasakan nyeri yang lebih hebat dari pada anak-anak yang usianya lebih tua. Manajemen nyeri yang dilakukan selama prosedur diharapkan akan mengurangi nyeri serta pengalaman emosional dan sosial yang negatif, seperti kecemasan, ketakutan, dan distress (Sonmezer, 2014). Manajemen nyeri yang digunakan, terbagi menjadi dua pendekatan, yaitu farmakologi dan nonfarmakologi. Penanganan nyeri secara non farmakologis dapat melalui distraksi. Penggunaan teknik non farmakologi memberikan dampak yang cukup berarti dalam manajemen nyeri pada anak (Baulch, 2010).

Terapi musik merupakan intervensi non farmakologik yang dapat mengurangi nyeri dan meningkatkan kesehatan fisik maupun mental. Sebagian peneliti berpendapat bahwa manejemen nyeri non farmakologis seperti nyeri akut, nyeri kronik ataupun nyeri akibat prosedur invasive dan beberapa prosedur medis lainnya dapat di lakukan dengan terapi musik untuk meredakan dan mengurangi nyeri. Terapi musik merupakan salah satu pengobatan komplementer yang bisa diterapkan setiap waktu tanpa adanya efek samping yang serius (Purwati, 2010). 
Terapi musik bekerja memberi pengaruh paling baik untuk jangka waktu yang singkat, untuk mengatasi nyeri intensif hanya berlangsung beberapa menit, misalnya selama pelaksanaan prosedur invasif atau saat menunggu kerja analgesik. Tujuan penggunaan teknik terapi musik dalam intervensi keperawatan adalah untuk pengalihan atau menjauhi perhatian terhadap sesuatu yang sedang dihadapi, misalnya rasa sakit (nyeri). Sedangkan manfaat dari penggunaan teknik ini, yaitu agar seseorang yang menerima teknik ini merasa lebih nyaman, santai, dan merasa berada pada situasi yang lebih menyenangkan (Firman, 2011).

Alimul (2009), menyatakan bahwa musik dapat menciptakan suasana nyaman pada situasi yang tidak nyaman seperti nyeri post operasi. Mc Caffrey telah melakukan penelitian tentang terapi musik untuk penurunan nyeri pada osteoartritis, dia mendapatkan hasil bahwa pasien yang diberi terapi musik selama 20 menit merasakan nyerinya berkurang sebanyak 33\%. Distraksi mendengarkan musik pada intra operasi dan post operasi dapat menurunkan nyeri. Mereka menyimpulkan bahwa musik mempunyai efek langsung jangka pendek dalam menurunkan nyeri (Alimul, 2009).

Berdasarkan data Rekam Medis Rumah Sakit Harapan dan Doa tahun 2017 jumlah kunjungan pasien anak berjumlah 1511, tahun 2018 berjumlah 1635 dan selama satu tahun terakhir 2019 sebanyak 1305 orang jumlah pasien anak yang mendapatkan terapi intravena Rumah Sakit Harapan dan Doa tahun 2019. Berdasarkan latar belakang di atas, maka peneliti tertarik untuk melakukan penelitian dengan judul Pengaruh Terapi Musik Terhadap Tingkat Nyeri Tindakan Pemasangan Infus pada anak usia 6-12 tahun di Rumah Sakit Harapan dan Doa.

\section{METODE}

Peneliti menggunakan desain pre eksperimen dengan rancangan desain one grup pre-post test rancangan one group pre post test ini tidak ada kelompok pembanding (kontrol), Notoatmodjo (2010). Langkah pertama dilakuakan dilakukan observasi pertama (pretest) yaitu penilaian nyeri sebelum tindakan terapi musik. Langkah kedua semua responden diberikan tindakan terapi musik, 
dan langkah ke tiga dilakukan observasi (postest) yaitu penilaian nyeri setelah tindakan terapi musik.

Populasi dalam penelitian ini adalah semua pasien anak usia 6-12 tahun yang terpasang infus 1305 kasus tahun 2019. Sampel merupakan bagian dari populasi yang akan diteliti atau sebagian dari jumlah karakteristik yang dimiliki populasi. Untuk pengambilan jumlah sampel kasus dilakukan dengan tehnik accidental sampling. Sugiyono (2013) dikarenakan keterbatasan waktu maka diambil sampel yang dipakai pada penelitian ini adalah 10 pasien yang dilakukan distraksi dan 10 pasien tidak dilakukan.

\section{HASIL}

\section{Analisis Univariat}

Tabel 1. Rata-Rata Nyeri Sebelum Dilakukan Terapi Musik Pada Pada Anak Usia 6-12 Tahun Di Rumah Sakit Harapan Dan Doa

\begin{tabular}{ccccc}
\hline Tingkat Nyeri & Mean & Median & SD & Min-Max \\
\hline $\begin{array}{c}\text { Tingkat nyeri sebelum } \\
\text { dilakukan trapi musik }\end{array}$ & 7,70 & 8,00 & 0,675 & $7-9$ \\
\hline
\end{tabular}

Tabel 1 di atas, diketahui bahwa rata-rata nyeri sebelum dilakukan terapi musik pada pada anak usia 6-12 dengan nilai 7,70.

Tabel 2. Rata-rata nyeri setelah dilakukan terapi musik pada pada anak usia 6-12 tahun di Rumah Sakit Harapan dan Doa

\begin{tabular}{ccccc}
\hline Tingkat Nyeri & Mean & Median & SD & $\begin{array}{c}\text { Min- } \\
\text { Max }\end{array}$ \\
\hline $\begin{array}{c}\text { Tingkat nyeri sesudah } \\
\text { diberikan terapi musik }\end{array}$ & 5,80 & 6,00 & 0,632 & $5-7$ \\
\hline
\end{tabular}

Tabel 2 di atas, diketahui bahwa rata-rata nyeri sesudah dilakukan terapi musik pada pada anak usia 6-12 dengan nilai 5,80 


\section{Analisis Bivariat}

Tabel 3. Pengaruh Terapi Musik Terhadap Tingkat Nyeri Tindakan Pemasangan Infus pada anak usia 6-12 tahun di Rumah Sakit Harapan dan Doa

\begin{tabular}{lccccc}
\hline \multicolumn{1}{c}{ Variabel } & Mean & SD & SE & $\boldsymbol{\rho}$ Value & N \\
\cline { 1 - 3 } $\begin{array}{l}\text { Sebelum diberikan terapi } \\
\text { musik }\end{array}$ & 7,70 & 6,57 & 0,213 & 0,000 & 10 \\
\cline { 1 - 3 } $\begin{array}{l}\text { Setelah diberikan terapi } \\
\text { musik }\end{array}$ & 5,80 & 6,32 & 0,200 & & \\
\hline
\end{tabular}

Tabel 3 di atas dapat dilihat bahwa nilai mean atau rata-rata sebelum diberikan terapi musik adalah 7,70, sedangkan nilai mean atau rata-rata sesudah diberikan terapi musik adalah 5,80 Hasil uji statistic didapatkan nilai $\rho=0,000<\alpha$ $(0,05)$, maka dapat disimpulkan bahwa ada pengaruh sebelum diberikan terapi musik dan sesudah diberikan terapi musik pada anak usia 6-12 Tahun Di Rumah Sakit Harapan dan Doa.

\section{PEMBAHASAN}

Berdasarkan tabel 4 di atas, menunjukan bahwa pemasangan infus sebelum dilakukan terapi musik dengan jumlah rata-rata skore skala nyeri 7,70 dan standar deviasi 6,75 . Hal ini sesuai dengan penelitian yang dilakukan peneliti di lapangan bahwa didapatkan pasien anak pada saat di bawak ke RSUD mereka sudah merasakan takut dan cemas dan bahkan menangis sehingga pada saat akan dilakukan pemsangan infus pasien tidak mendapatkan terapi musik sehingga pada saat dilakukan tindakan pemasangan infus seluruh pasien menunjukan nyeri yang berat.

Reaksi terhadap nyeri cenderung sama dengan yang terlihat pada masa toddler, meskipun beberapa perbedaan menjadi jelas. Misalnya, respon anak prasekolah terhadap intervensi persiapan dalam hal, penjelasan dan distraksi lebih baik dibandingkan dengan respon anak yang lebih kecil. Anak usia 6- 12 tahun dapat menunjukkan letak nyeri mereka dan dapat menggunakan skala nyeri dengan tepat (Wong, 2009). 
Berdasarkan tabel 4 di atas, menunjukan bahwa pemasangan infus yang sesudah dilakukan terapi musik dengan jumlah rata-rata skore skala nyeri 5,80 dan standar deviasi 6,32. Hal ini sesuai dengan penelitian yang dilakukan peneliti di lapangan bahwa didapatkan pasien anak yang dilakukan terapi musik pada saat pemasangan infus menunjukan tingkat nyeri sedang ini dikarenakan anak di dengarkan musik kesukaan mereka sehingga membuat anak rileks dan tenang membuat nyeri pada saat tindakan pemsangan infus teralihkan dengan suara musik yang mereka dengarkan.

Alimul (2009), menyatakan bahwa musik dapat menciptakan suasana nyaman pada situasi yang tidak nyaman seperti nyeri post operasi. Penelitian tentang terapi musik untuk penurunan nyeri pada osteoartritis, dia mendapatkan hasil bahwa pasien yang diberi terapi musik selama 20 menit merasakan nyerinya berkurang sebanyak 33\%. Distraksi mendengarkan musik pada intra operasi dan post operasi dapat menurunkan nyeri. Mereka menyimpulkan bahwa musik mempunyai efek langsung jangka pendek dalam menurunkan nyeri (Alimul, 2009). Terapi musik juga merupakan intervensi non farmakologik yang dapat mengurangi nyeri dan meningkatkan kesehatan fisik maupun mental. Sebagian peneliti berpendapat bahwa manejemen nyeri non farmakologis seperti nyeri akut, nyeri kronik ataupun nyeri akibat prosedur invasive dan beberapa prosedur medis lainnya dapat di lakukan dengan terapi musik untuk meredakan dan mengurangi nyeri.Terapi musik merupakan salah satu pengobatan komplementer yang bisa diterapkan setiap waktu tanpa adanya efek samping yang serius (Purwati, 2010).

Berdasarkan tabel 3 diatas diketahui nilai $\rho=0,000<\alpha(0,05)$, maka dapat disimpulkan bahwa ada pengaruh antara terapi musik pada pemasangan infus pada anak terhadap tingkat nyeri. Nilai mean atau rata-rata tingkat nyeri sebelum dilakukan terapi musik adalah 7,70, sedangkan nilai mean atau rata-rata tingkat nyeri sesudah dilakukan terapi musik adalah 5,80. Terapi musik yang memfokuskan perhatian pasien pada sesuatu selain pada nyeri, dapat menjadi strategi yang sangat berhasil dan mungkin merupakan mekanisme terhadap teknik kognitif efektif lainnya. Terapi musik diduga dapat menurunkan persepsi nyeri dengan menstimulasi system kontrol desenden, yang mengakibatkan lebih sedikit 
stimuli nyeri yang ditransmisikan ke otak. Penelitian ini sejalan dengan pendapat Firman (2011), yang menyatakan bahwa terapi musik bekerja memberi pengaruh paling baik untuk jangka waktu yang singkat, untuk mengatasi nyeri intensif hanya berlangsung beberapa menit, misalnya selama pelaksanaan prosedur invasif atau saat menunggu kerja analgesik. Tujuan penggunaan teknik terapi musik dalam intervensi keperawatan adalah untuk pengalihan atau menjauhi perhatian terhadap sesuatu yang sedang dihadapi, misalnya rasa sakit (nyeri). Sedangkan manfaat dari penggunaan teknik ini, yaitu agar seseorang yang menerima teknik ini merasa lebih nyaman, santai, dan merasa berada pada situasi yang lebih menyenangkan (Firman, 2011).

Musik memberikan kesempatan bagi tubuh dan pikiran untuk mengalami relaksasi yang sempurna. Kondisi relaksasi yang sempurna itu seluruh sel dalam tubuh akan mengalami reproduksi penyembuhan alami yang akan berlangsung, produksi hormone tubuh diseimbangkan dan pikiran mengalami penyegaran (Demir, 2011). Alimul (2009), menyatakan bahwa musik dapat menciptakan suasana nyaman pada situasi yang tidak nyaman seperti nyeri post operasi. Mc Caffrey telah melakukan penelitian tentang terapi musik untuk penurunan nyeri pada osteoartritis, dia mendapatkan hasil bahwa pasien yang diberi terapi musik selama 20 menit merasakan nyerinya berkurang sebanyak 33\%. Distraksi mendengarkan musik pada intra operasi dan post operasi dapat menurunkan nyeri. Mereka menyimpulkan bahwa musik mempunyai efek langsung jangka pendek dalam menurunkan nyeri (Alimul, 2009).

\section{SIMPULAN DAN SARAN}

\section{SIMPULAN}

a. Responden sebelum dilakukan terapi musik rata-rata tingkat nyeri 7,70

b. Responden sesudah dilakukan terapi musik rata-rata tingkat nyeri 5,80

c. Ada pengaruh terapi musik terhadap tingkat nyeri pada pemasanag infus pada anak. 


\section{SARAN}

Hasil penelitian ini dapat menjadi masukan atau informasi Bagi petugas Rumah Sakit Harapan dan Doa perlu adanya meningkatkan pelayanan kesehatan secara menyeluruh terutama tentang penangan intensitas nyeri yang teknik non farmakologi yaitu terapi musik. Penelitian ini dapat dijadikan motivasi untuk mempertahankan dan meningkatkan pelayanan kesehatan secara menyeluruh terutama tentang penangan intensitas nyeri yang teknik non farmakologi yaitu terapi musik. Diharapkan dapat menambah pengetahuan dan wawasan bagi perawat, serta kepuasan pasien dan keluarga dalam teknik distraksi terhadap intensitas nyeri pada pasien anak.

\section{DAFTAR RUJUKAN}

Alimul, Aziz. A. (2009). Pengantar Kebutuhan Dasar Manusia, Aplikasi Konsep dan Proses Keperawatan: Salemba Medika. Jakarta.

Baulch, I. (2010). Assessment and Management of Pain in the Paediatric Patient. Nursing Standard, 25 (10)

Demir, Elif Senem. 2008. Cinema Therapy. Psychology Jurnal Of Metu. (http://psinema.metu.edu.tr/makale/ cinematherapy.pdf).

Firman. (2012). Efektifitas Terapi Murottal dan Terapi Musik Klasik Terhadap Penurunan Tingkat Kecemasan Pasien Pra Operasi di Pekalongan. STIKes Muhammadiya Pekajangan Pekalongan. Pekalongan.

Hockenberry, J.M. \& Wilson, D., (2009). Wong: Essentials of Pediatric Nursing 8 ed. Philadelphia: Mosby Elsevier

Maryam dkk., (2012). Pengaruh Guided Imagery terhadap nyeri anak usia 7-13 tahun saat dilakukan pemasangan infus. PROSIDING Seminar Nasional dan Internasional Universitas Muhammadiyah Semarang.

Purwarti, (2010). Konsep dan proses keperawatan nyeri. Yogyakarta: Graha Ilmu

Sikorova, L., \& Hrazdilova, P. (2011). The effect psychological intervention on perceived pain in children undergoing venepuncture. Biomedical Papers, $155(2)$.

Sonmezer, H. (2014). Efficacy of distraction methods on procedural pain and anxiety by applying cards and kaleidoscope in children. Asian Nursing Research, 8. 
Sugiyono, P. (2013). Metodologi Penelitian Kuantitatif dan Kualitatif. Bandung: Alfabeta.

Wong, (2013). Nursing care of infants and children. St. Luis: Mosby Yanuarita, 2012 Psikologi Musik. Yogyakarta: Best Publisher. 